\title{
Anomalous changes of temperature and ozone QBOs in 2015-2017 from radiosonde observation and MERRA-2 reanalysis
}

\author{
XiaoYan Bai 1,2,3, KaiMing Huang 1,2,3* , ShaoDong Zhang 1,2, ChunMing Huang1,2, and Yun Gong 1,2 \\ 'School of Electronic Information, Wuhan University, Wuhan 430072, China; \\ ${ }^{2}$ Key Laboratory of Geospace Environment and Geodesy, Ministry of Education, Wuhan 430072, China; \\ ${ }^{3}$ State Observatory for Atmospheric Remote Sensing, Wuhan 430072, China \\ Key Points: \\ - Temperature QBO (quasi-biennial oscillation) has the shortest cold phase in winter 2015-2016 but is not interrupted. \\ - Meridional scale reduction of temperature QBO causes a small temperature anomaly in anomalous QBO event. \\ - A double-peak structure in ozone QBO occurs with inverse phase around $30 \mathrm{~km}$ because of different control mechanisms of ozone.
}

Citation: Bai, X. Y., Huang, K. M., Zhang, S. D., Huang, C. M. and Gong, Y. (2021). Anomalous changes of temperature and ozone QBOs in 2015-2017 from radiosonde observation and MERRA-2 reanalysis. Earth Planet. Phys., 5(3), 280-289. http://doi.org/10.26464/epp2021028

\begin{abstract}
Anomalous changes of zonal wind quasi-biennial oscillation (QBO) in winter 2015-2016 have received close attention. Combining radiosonde and satellite observations and reanalysis data, we investigate anomalous changes in temperature and ozone QBOs from the lower to middle stratosphere. As wind shear direction is reversed due to unexpected changes of zonal wind QBO at about 24-30 km, the shortest cold phase at 21-27 km appears in temperature QBO. This is different from the completely interrupted westward phase in zonal wind QBO, while the longest cold phase above almost $27 \mathrm{~km}$ lasts for 2-3 years from 2015 to 2017 , owing to the absence of corresponding warm phase. Meridional scale reduction of temperature QBO causes a small temperature anomaly, thus the thermal wind relationship looks seemingly different from that in the other regular QBO cycles. QBO in the ozone mixing ratio anomaly shows a double-peak with inverse phase, and its phase below (above) $30 \mathrm{~km}$ is in agreement with (opposite to) the phase of temperature QBO because of different control mechanisms of ozone. Following temperature QBO variation, QBO in the ozone mixing ratio anomaly exhibits a less positive phase at 20-30 km in 2016-2017, and a very long positive phase above $30 \mathrm{~km}$ from 2015 to 2017 . QBO in total column ozone shows a small peak in winter 2016-2017 since ozone is mainly concentrated at 20 to $30 \mathrm{~km}$. Anomalous changes of temperature and ozone QBOs due to unexpected QBO zonal wind variation can be well-explained according to thermal wind balance and thermodynamic balance.
\end{abstract}

Keywords: QBO; temperature anomaly; ozone anomaly; thermal wind balance

\section{Introduction}

Quasi-biennial oscillation (QBO) is the dominant oscillation in the tropical stratosphere, featuring alternately eastward and westward wind regimes that repeat at intervals varying from 22 to 36 months, with an average period of approximately 28 months (Baldwin et al., 2001). Over the equator, the QBO amplitude is more than $30 \mathrm{~m} \cdot \mathrm{s}^{-1}$, and the westward wind is generally stronger than the eastward wind. The alternating wind bands propagate downward at a speed of roughly $1 \mathrm{~km}$ per month, and the eastward wind phase moves downward faster than the westward wind phase (Naujokat, 1986; Pascoe et al., 2005). Interactions between the mean zonal wind and vertically propagating internal waves generated in the tropical troposphere are believed to largely cause the mean wind accelerations driving the QBO

Correspondence to: K. M. Huang, hkm@whu.edu.cn

Received 14 DEC 2020; Accepted 31 MAR 2021.

Accepted article online 22 APR 2021.

C 2021 by Earth and Planetary Physics.
(Holton and Lindzen, 1972; Dunkerton, 1997; Huang KM et al., 2009; Xue XH et al., 2012). Although it is a tropical phenomenon, the QBO can affect the stratospheric polar vortex mainly through the shift of the subtropical critical line in the lower stratosphere, and through the change in mean meridional circulation in the upper stratosphere (Rao J and Ren RC, 2017; Rao J et al., 2019, 2020a). It also can affect the severity of high-latitude ozone depletion and the global stratospheric circulation through modulating extratropical wave propagation (McCormack and Siskind, 2002). The circulation changes induced by the QBO can further affect the distribution of chemical constituents, such as water vapor, ozone, and methane (Wallace et al., 1993; Lee et al., 2010; Liu JH et al., 2020). Rao J et al. (2020b) explores and evaluates the three dynamical pathways for impacts of the QBO on tropospheric circulation by using 17 CMIP5 and CMIP6 models. Hence, the QBO and its global influence have attracted close attention since the QBO was discovered by Ebdon (1960) and Reed et al. (1961) from radiosonde observations at equatorial stations.

There are also substantial QBO signals in temperature, ozone and 
many shorter-lived chemical constituents. The QBO is the major interannual variation of tropical stratospheric temperature (Dunkerton and Delisi, 1985; Randel and Cobb, 1994). The equatorial temperature anomalies associated with the QBO in the lower stratosphere are on the order of $\pm 4 \mathrm{~K}$, with a maximum value around $30-50 \mathrm{hPa}$, and decreases to about $\pm 0.5 \mathrm{~K}$ near the tropopause (Randel et al., 1999; Baldwin et al., 2001). The temperature QBO in the tropics is in thermal wind balance with the vertical shear of zonal winds (Andrews et al., 1987), which means that a warm (cold) temperature anomaly is associated with the eastward (westward) shear of the QBO zonal wind. Moreover, the warm (cold) temperature anomaly induces a relative adiabatic descent (ascent) through radiative cooling (heating) (Plumb and Bell, 1982), thus the zonal wind QBO is accompanied by variations in temperature and vertical motion.

Ozone is an important greenhouse gas and affects radiative balance of the atmosphere. The zonal wind and temperature QBOs dominate the interannual variability of ozone in the tropical stratosphere (Tegtmeier et al., 2010), causing ozone to exhibit an evident QBO signal. Many observations indicate that the ozone QBO in the tropics displays a double-peak structure (Zawodny and McCormick, 1991; Hasebe, 1994; Fadnavis and Beig, 2009; Tegtmeier et al., 2010). The phase of the ozone QBO in the middle stratosphere is almost opposite to that in the lower stratosphere due to a phase reversal at about $28-30 \mathrm{~km}$. The ozone and zonal wind QBOs in the lower stratosphere are approximately a quarter cycle out of phase. The temperature QBO phase descends faster than the ozone QBO phase (Fadnavis and Beig, 2009), and they have an in-phase relationship in the lower stratosphere but an anti-phase relationship in the middle stratosphere. Photochemical lifetime of ozone decreases with altitude (Garcia and Solomon, 1985; Jones et al., 1998). In the lower stratosphere, the photochemical lifetime is longer than advective time scales, thus ozone is mainly under dynamical control via vertical transport. Since the ozone mixing ratio in the lower stratosphere increases with height, the downward moving flow over the equator brings ozone-rich air from higher levels to increase the ozone amount, and vice versa. As the height increases, dynamical control of ozone is gradually replaced with photochemical control. In this case, the ozone abundance is sensitive to the temperature that impacts the reaction rate of ozone destruction (Ling XD and London, 1986; Fleming et al., 2002). Hence, the different control mechanisms determine the double-peak structure of the zone QBO.

The radiosonde observation at the equatorial station shows an anomalous change in the zonal wind QBO in 2015-2016 (Newman et al., 2016; Osprey et al., 2016; Rao J and Ren RC, 2017; Li HY et al., 2020), which is the only disruption to the regular QBO propagation in the data record between 1953 and 2016. In January 2016, the expected downward propagating westward phase stalled and was temporarily displaced by an upward propagating eastward phase from about $40 \mathrm{hPa}$ up to $10 \mathrm{hPa}$, and then the stalling was followed by the unexpected formation of a second westward wind near $40 \mathrm{hPa}$, interrupting the lower stratospheric eastward phase. This abnormal QBO began developing from December 2015 , resulting in the shortest westward (eastward) wind phase at $10 \mathrm{hPa}(40 \mathrm{hPa})$ observed in the 1953-2016 record. The westward wind near $40 \mathrm{hPa}$ formed within the eastward phase was driven through momentum transported by planetary Rossby waves from the extratropical zone in the Northern Hemisphere $(\mathrm{NH})$, instead of the standard QBO paradigm based on vertical momentum transport (Dunkerton, 2016; Newman et al., 2016; Osprey et al., 2016); in the canonical QBO model, vertically propagating Rossby waves deposit their momentum in a strong westward wind shear. The examination of tropical zonal momentum budget showed that there were record maxima in the horizontal momentum fluxes and wave forcing from Rossby waves and mixed Rossbygravity waves over the winter of 2015-2016, especially at the $40 \mathrm{hPa}$ level (Coy et al., 2017; Barton and McCormack, 2017; Lin P et al., 2019). As the westward wind developed near $40 \mathrm{hPa}$, eastward acceleration appeared above $40 \mathrm{hPa}$ due to the forcing by upward propagating Kelvin waves (Newman et al., 2016; Osprey et al., 2016). Li HY et al. (2020) demonstrated that not only Rossby waves propagating from the northern extratropics were important contributors to the eastward acceleration around $40 \mathrm{hPa}$, but also from local wave generation by analyzing the horizontal momentum flux anomaly from Rossby waves in the extratropics and tropics. Hence, the wave activities seem to be a good explanation of the anomalous change in the zonal wind QBO.

The possible causes for the anomalous QBO are revealed through observational and modeling studies. However, most of the relevant studies focused on the variation in zonal wind $\mathrm{QBO}$, in particular, its onset in the lower stratosphere, while the corresponding QBOs in temperature and ozone drew less attention. In this paper, we investigate the QBO structures of temperature and ozone in the lower and middle stratosphere based on radiosonde and satellite measurements and reanalysis data. We present anomalous QBOs in temperature and ozone during 2015-2017, and discuss the connections among the anomalous changes in zonal wind, temperature and ozone. In the following section, we briefly describe the datasets used in the paper, and then analyze the anomalous QBOs in zonal wind, temperature and ozone, and their relationship in section 3 . In section 4 , a summary is given.

\section{Data Description}

In this paper, by using United States radiosonde observations, Aura satellite ozone measurements, and Modern-ERA Retrospective Analysis for Research and Applications version 2 (MERRA-2) reanalysis data for 21 years from January 1998 to December 2018, we study the QBOs in zonal wind, temperature and ozone, in particular, the anomalous changes between 2015 and 2017.

The radiosonde data is provided by the National Oceanic and Atmospheric Administration (NOAA) National Climatic Data Center (NCDC) through the stratospheric processes and their role in climate (SPARC) data center at the website of http://www. sparc.sunysb.edu/. From the dataset, we analyze the zonal wind and temperature data at Ponape Island $\left(6.97^{\circ} \mathrm{N}, 158.22^{\circ} \mathrm{E}\right)$, as a tropical station closest to the equator. Radiosonde is routinely launched twice daily at 00:00 and 12:00 UT, and with the ascent of the balloon, meteorological parameters, such as atmospheric temperature, horizontal wind, pressure, and relative humidity are sampled with an interval of $6 \mathrm{~s}$, resulting in an irregular height resolution due to the change in the rising speed of radiosonde. For 
convenience, the data are linearly interpolated every $50 \mathrm{~m}$. In the period that we focus on, about $60 \%$ of balloons reached the height of $30 \mathrm{~km}$, thus we select this altitude as the upper limit of radiosonde measurement.

Total column ozone (TCO) from the ozone monitoring instrument (OMI) aboard the National Aeronautics and Space Administration (NASA) Earth Observing System (EOS) Aura satellite is used to investigate the ozone variation. The TCO algorithm is based on the differential optical absorption spectroscopy technique; the algorithm features and error analysis are described in detail by Veefkind et al. (2006). The available TCO data from OMI are from October 2004, which is accessed from the Tropospheric Emission Monitoring Internet Service (TEMIS) project of the European Space Agency (ESA) Data User Programme (DUP) through the website at http://www.temis.nl/protocols/o3field/data/omi/. The data are provided at different stations, and we chose to analyze the TCO at three low latitude stations of Tarawa $\left(1.36^{\circ} \mathrm{N}, 172.92^{\circ} \mathrm{E}\right)$, Petaling $\left(3.1^{\circ} \mathrm{N}, 101.6^{\circ} \mathrm{E}\right)$ and Songkhia $\left(7.2^{\circ} \mathrm{N}, 100.6^{\circ} \mathrm{E}\right)$, relatively close to Ponape Island.

The MERRA-2 dataset is produced by the NASA Global Modeling and Assimilation Office (GMAO), which is retrieved at the website of https://disc.gsfc.nasa.gov/datasets/. The reanalysis data are 6hourly instantaneous analysis fields, including atmospheric temperature, wind, pressure, and ozone and vapor mixing ratio, etc., on a $0.5^{\circ} \times 0.625^{\circ}$ latitude-by-longitude grid at 72 model levels from the ground up to $0.01 \mathrm{hPa}$ (Gelaro et al., 2017).

\section{Results}

\subsection{QBO in Zonal Wind and Temperature}

By using the monthly mean zonal wind (positive eastward) and temperature derived from the radiosonde observation at Ponape Island for 21 years from January 1998 to December 2018, we remove their climatological mean values from the monthly mean series in order to clearly show the QBO in zonal wind and temperature. The climatological mean is calculated by averaging the monthly mean in the same months over 21 years, and then the monthly mean anomaly can be obtained by subtracting the climatological mean from the monthly mean series during the 21 years. Figure 1 depicts the zonal wind and temperature anomalies from the radiosonde observations. An unexpected change of the zonal wind QBO occurs in the winter of 2015-2016, and the downward moving westward wind is disrupted by the ascending eastward wind in the height range of $\sim 24-30 \mathrm{~km}$, which is in good agreement with equatorial observations in previous studies (Newman et al., 2016; Osprey et al., 2016). Meanwhile, it can be noted from Figure $2 \mathrm{~b}$ that the descending cold temperature phase is not completely cutoff in this winter, though the cold phase at 21-27 km is the shortest cold phase in the entire observation, and the next warm phase, with only a month duration at $27-30 \mathrm{~km}$, is also the shortest warm phase. In addition, the tropospheric warming from 2013 is seen with an increased temperature peak of about $2 \mathrm{~K}$ in the winter of 2015-2016. In Figure 1b, we use the black curves to plot the zero anomalies of temperature QBO, and then superim-

(a) Zonal wind anomaly in radiosonde observation

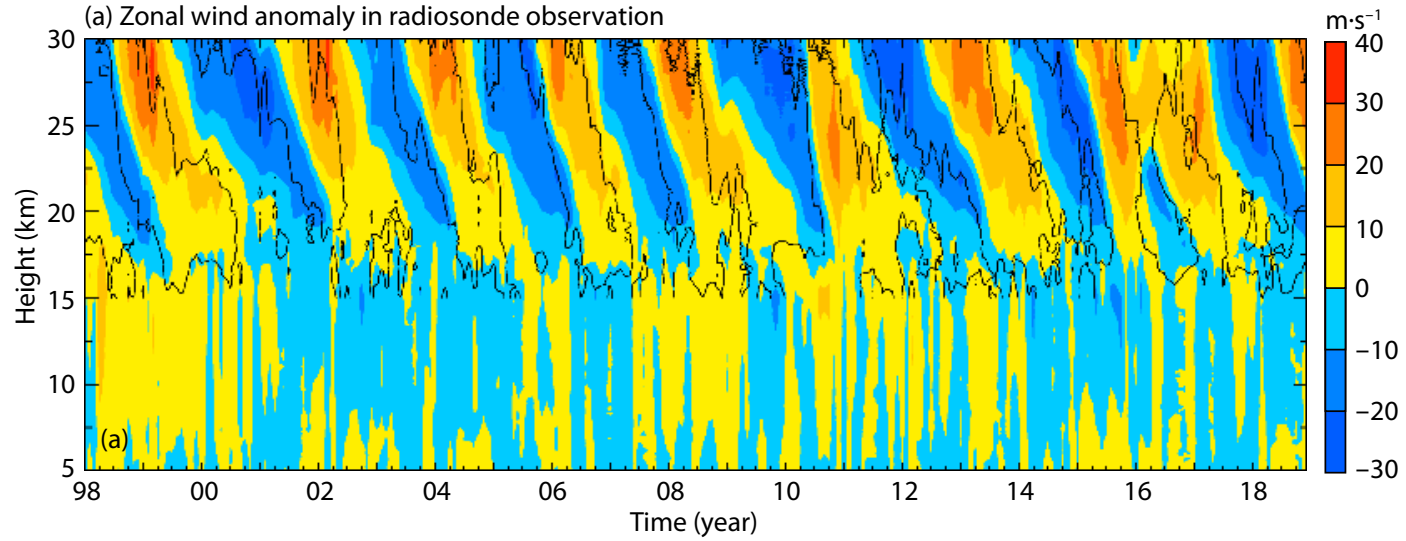

(b) Temperature anomaly in radiosonde observation

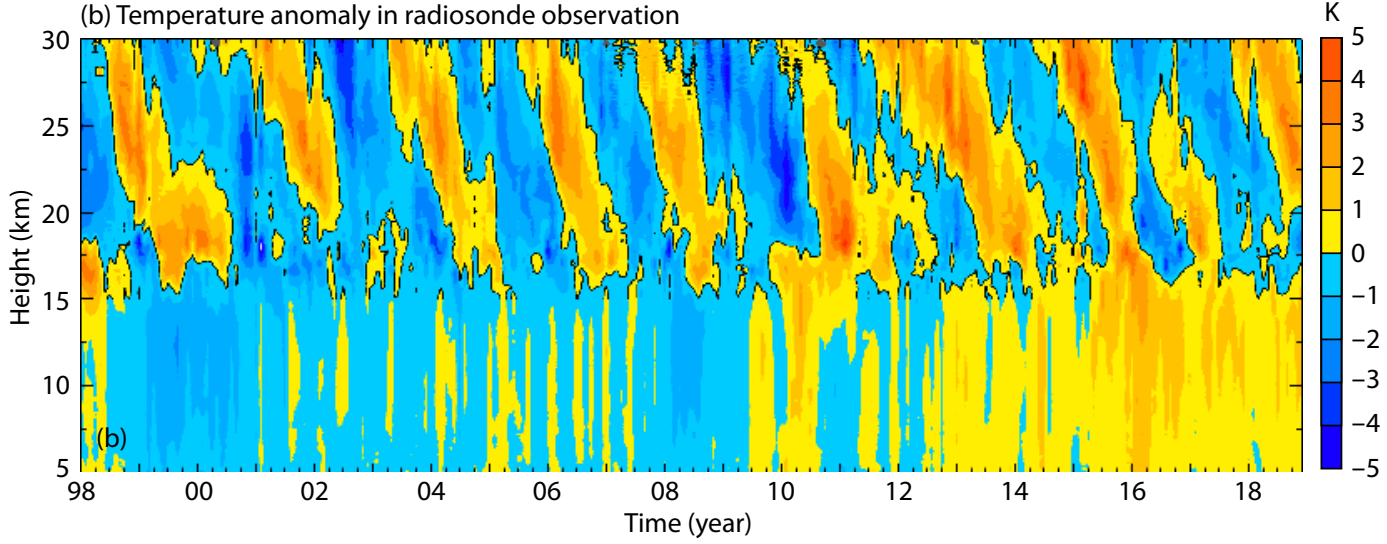

Figure 1. Time-height section of monthly mean (a) zonal wind and (b) temperature anomalies over Ponape Island derived from radiosonde observation. The black curves are the zero anomaly of the temperature QBO in the radiosonde observation. 
pose these zero curves on the zonal wind QBO in Figure 1a. By comparing the zero curves with the eastward wind phase, the alternating phase QBO pattern in temperature is similar to that in the zonal wind but with a phase lead of about $90^{\circ}$. This is consistent with the thermal wind balance that the temperature anomaly is associated with the vertical shear of the zonal wind QBO rather than the zonal wind QBO itself.

Based on the MERRA- 2 reanalysis data, we can examine the anomalous QBO at higher levels. Figure 2 shows the zonal wind and temperature anomalies over Ponape Island derived from the reanalysis data in the same period of 1998-2018, respectively. For comparison, we derive the zonal mean zonal wind between $5^{\circ} \mathrm{S}$ and $5^{\circ} \mathrm{N}$ from the reanalysis data, and then calculate its monthly mean anomaly, which is presented in Figure 3. Because the QBO is a global scale motion, it can be seen that there is nearly the same scenario of zonal wind QBOs in Figures 2 and 3, except the oscillation magnitudes. This indicates that the investigation of the anomalous QBO over Ponape Island is generalizable. In Figure 2, the QBOs in the zonal wind and temperature below $30 \mathrm{~km}$ are consistent with those in the radiosonde observation in Figure 2. Figure $3 a$ illustrates that the abnormal ascending eastward wind stops at about $35 \mathrm{~km}(\sim 6 \mathrm{hPa})$ in July 2016. In Figure 3b, it is interesting that an extremely long cold phase above $30 \mathrm{~km}$ (almost $27 \mathrm{~km}$ ) lasts for 2-3 years from 2015 to 2017, due to the absence of the corresponding warm phase. This is related to the anomalous $\mathrm{QBO}$ of the zonal wind, because a negative vertical wind shear corresponds to a cold temperature phase according to the thermal wind relationship. In the reanalysis data, the tropospheric warming in 2013-2018 is weaker than in the radiosonde observation.

\subsection{QBO Temperature and Wind Shear}

Because of the long timescale and equatorial symmetry of the $\mathrm{QBO}$, the thermal wind balance still holds throughout the equatorial region, which requires a temperature oscillation along with the wind oscillation. The thermal wind balance is expressed for the equatorial $\beta$-plane as (Andrews et al., 1987):

$$
u_{z}=-R(H \beta)^{-1} T_{y y}
$$

where $u$ and $u_{z}$ are the zonal wind and its derivative in the vertical direction; $R$ is the gas constant; $H=7 \mathrm{~km}$ is the scale height; $\beta$ is the Rossby parameter; and $T$ and $T_{y y}$ are the temperature and its second derivative in the meridional direction. For the $\mathrm{QBO}$ variations centered on the equator with a meridional scale $L$, the thermal wind relationship can approximately be written as (Andrews et al., 1987; Ribera et al., 2004):

$$
u_{z} \simeq\left(\frac{R}{H \beta}\right) \frac{\delta T_{\mathrm{QBO}}}{L^{2}},
$$

where $\delta T_{\mathrm{QBO}}$ is the temperature anomaly associated with the QBO. Here, we calculate the QBO temperature anomaly at $20 \mathrm{~km}$ $(56.4 \mathrm{hPa})$ and the wind shear between $20 \mathrm{~km}$ and $25 \mathrm{~km}(28.4 \mathrm{hPa}$ and $56.4 \mathrm{hPa}$ ) in the radiosonde observation (the reanalysis data). Figure 4 shows the temperature anomaly and vertical wind shear
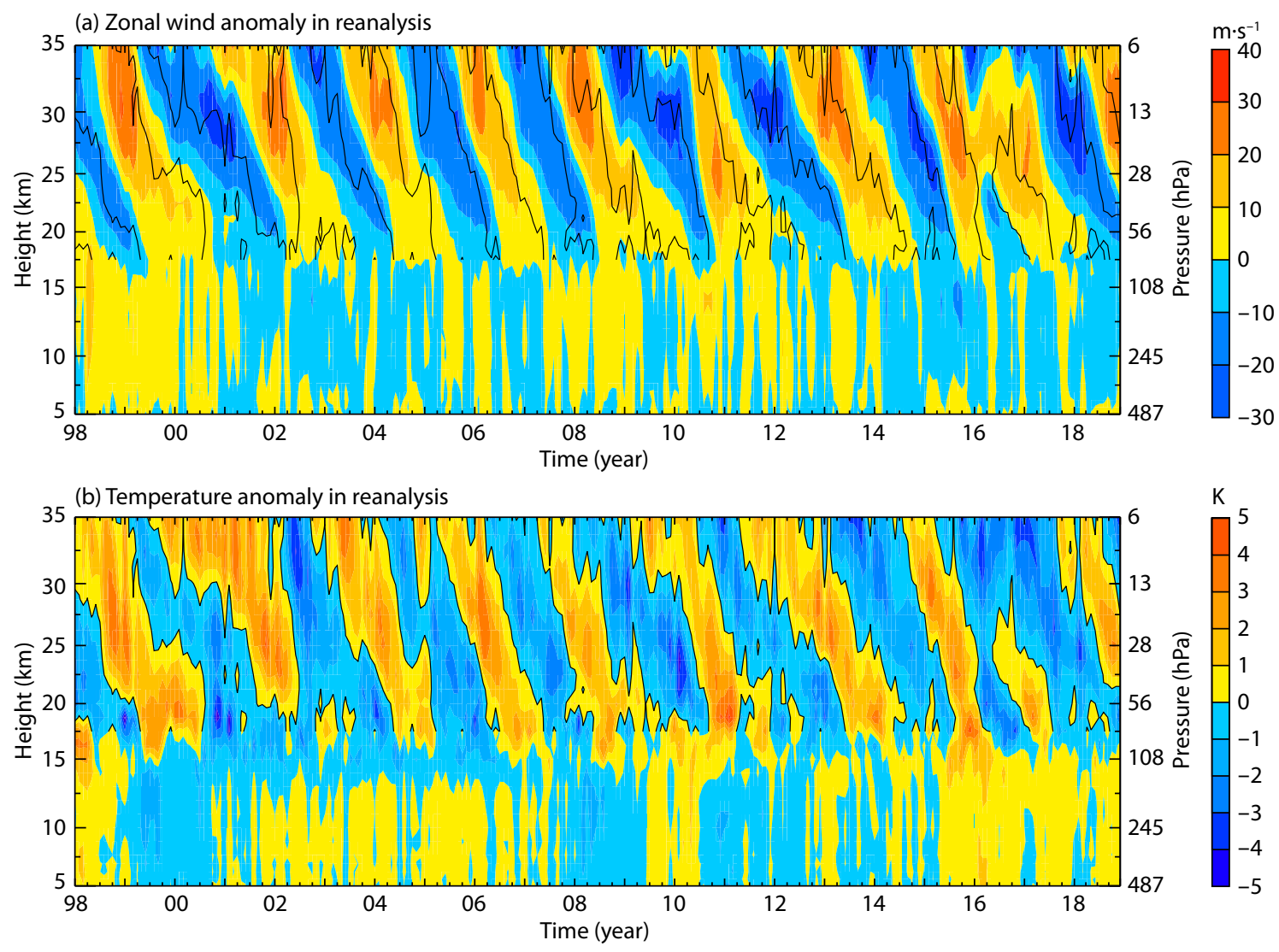

Figure 2. Time-height section of monthly mean (a) zonal wind and (b) temperature anomalies over Ponape Island derived from MERRA-2 reanalysis data. The black curves are the zero anomaly of the temperature $\mathrm{QBO}$ in the reanalysis data. 


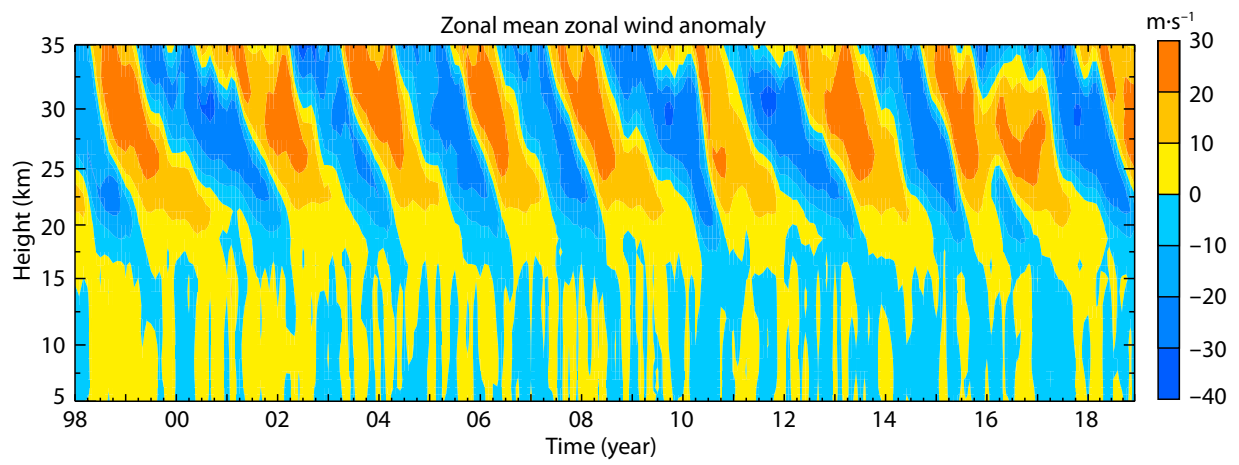

Figure 3. Time-height section of monthly mean zonal mean zonal wind anomaly between $5^{\circ} \mathrm{S}$ and $5^{\circ} \mathrm{N}$ derived from reanalysis data.

over Ponape Island derived from the radiosonde observation and reanalysis data, respectively. The QBO temperature anomalies over Ponape Island are very close to the order of $\pm 4 \mathrm{~K}$ in the equatorial region (Baldwin et al., 2001; Pascoe et al., 2005). As we expected, since the QBO temperature is in thermal wind balance with the vertical wind shear in the tropics, Figure 4 demonstrates that these two parameters are generally in phase such that the time of the maximum eastward (westward) shear corresponds to the warmest (coldest) period of temperature, which is consistent with the results at the equator derived from the EAR-40 reanalysis data (Pascoe et al., 2005).

Even so, there are two notable events in both the observation and reanalysis. One is a sudden temperature rise from June 2011, but a corresponding variation does not occur in the wind shear. The sudden temperature rise is coincident with the Icelandic Grims- votn volcano eruption on 21-22 May 2011 (Kerminen et al., 2011; Tesche et al., 2012), from which large amounts of volcanic ash grounded many flights around the world. The volcano eruption also caused a massive increase in stratospheric aerosols and water vapor with an e-folding residence time of about 1 year, which heats the stratosphere by absorbing terrestrial longwave radiation and solar infrared radiation. The other notable event is the large vertical wind shear versus the small temperature anomaly from the winter of 2015-2016 to the spring of 2017. The eastward wind takes the place of the normal westward wind at $40-10 \mathrm{hPa}$ levels (Osprey et al., 2016; Newman et al., 2016; Dunkerton, 2016), thus the abnormal eastward wind significantly enhances the wind shear between $28.4 \mathrm{hPa}$ and $56.4 \mathrm{hPa}$ levels ( $25 \mathrm{~km}$ and $20 \mathrm{~km})$.

There are different causes for the two events. In 2011-2012, the stratospheric temperature rise is mainly due to the volcano erup-

(a) Radiosonde observation

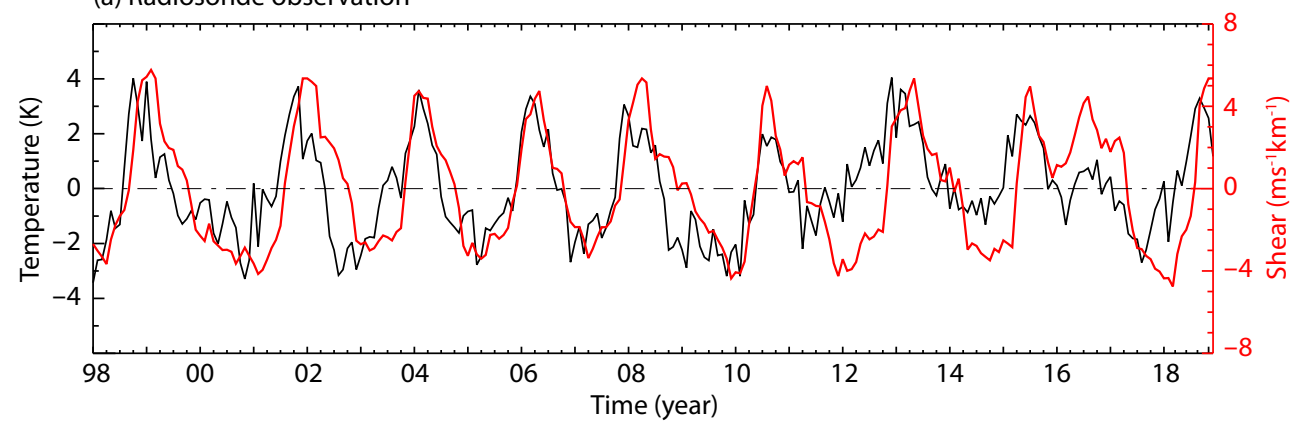

(b) Merra-2 reanalysis

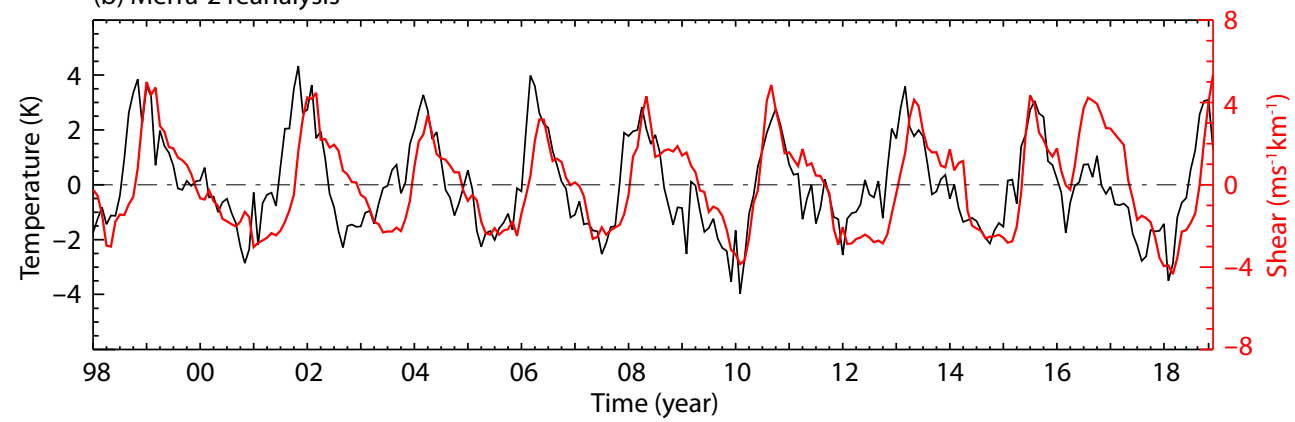

Figure 4. Thermal wind relationship between temperature anomaly and zonal wind shear derived from (a) radiosonde observation and (b) reanalysis data at Ponape Island during 1998-2018. The temperature anomaly is at $20 \mathrm{~km}$ in the radiosonde observation and at $56.4 \mathrm{hPa}$ level in the reanalysis data, and the wind shear is calculated between $20 \mathrm{~km}$ and $25 \mathrm{~km}$ in the radiosonde observation and between $28.4 \mathrm{hPa}$ and $56.4 \mathrm{hPa}$ levels in the reanalysis data. 
tion superimposed on the QBO temperature anomaly. In the second event, we investigate the QBO latitudinal scale further. Figure 5 shows the latitude-time section of monthly mean zonal wind and temperature anomalies at $28.4 \mathrm{hPa}$ between $20^{\circ} \mathrm{S}$ and $20^{\circ} \mathrm{N}$, along the $158.13^{\circ} \mathrm{E}$ meridian line derived from reanalysis data. At the $28.4 \mathrm{hPa}$ level, the anomalous QBO in the zonal wind is very clear with a westward phase of only 1-2 months. It is interesting that the meridional extension of the temperature QBO in 2016 is obviously smaller than that in the other years. This means that the anomalous QBO event causes a smaller meridional scale in the temperature QBO. According to expression (2), a smaller meridional scale corresponds to a smaller QBO temperature anomaly under a constant wind shear. Hence, the change of the zonal wind $\mathrm{QBO}$ leads to the corresponding variation of the temperature $\mathrm{QBO}$, not only in the vertical direction but also in the meridional direction due to the thermal wind relationship.

\subsection{QBO in Ozone}

Next, we investigate ozone changes in the anomalous QBO event. Figure 6 presents the monthly mean TCO (in Dobson Units) at three tropical stations, derived from the OMI observational data between January 2005 and December 2018. The predominant periodicity of the TCO is the annual oscillation (AO) with maxima in summer and minima in winter, and the $A O$ is apparently modulated by QBO, especially near the equator. In order to uncover the interannual variability, we derive the TCO anomaly, which is depicted in Figure 7. The QBO signal in the TCO anomaly is evident, and its magnitude tends to decrease with increasing latitude, though the TCO magnitude does not display an obvious variation from Tarawa to Songkhia. At all three stations, the normal reduction phase of the TCO anomaly stops suddenly and turns into a slow growth phase in the winter of 2015-2016; moreover, in this increasing phase, the peak of the ozone QBO in the winter of 2016-2017 is clearly smaller than that of the other QBO cycles. This indicates that the anomalous change also occurs in the ozone QBO.

Based on the reanalysis data of the ozone mixing ratio over Ponape Island, we calculate the monthly mean ozone mixing ratio anomaly from the troposphere to the stratosphere, which is presented in Figure 8. Figure 8 shows the evolution of the ozone QBO from the middle to lower stratosphere with alternate descending positive and negative phases. The ozone QBO in the lower stratosphere $\sim 20-30 \mathrm{~km}$ has a maximum amplitude around $27 \mathrm{~km}$, and is anti-phase with that in the middle stratosphere of about 30-35 km; thus the ozone QBO pattern is different from the QBOs in the zonal wind and temperature with coherent downward propagation phases. In order to investigate the relationship between the ozone and temperature QBOs, we superimpose the zero lines of the temperature $\mathrm{QBO}$ on the ozone anomaly. In the thermodynamic equation, the vertical eddy heat flux convergence and mean horizontal heat advection, with little variability, may be neglected (Weaver et al., 1993), especially for their monthly mean variations (Eluszkiewicz et al., 1996). In this case,

(a) Zonal wind anomaly in reanalysis

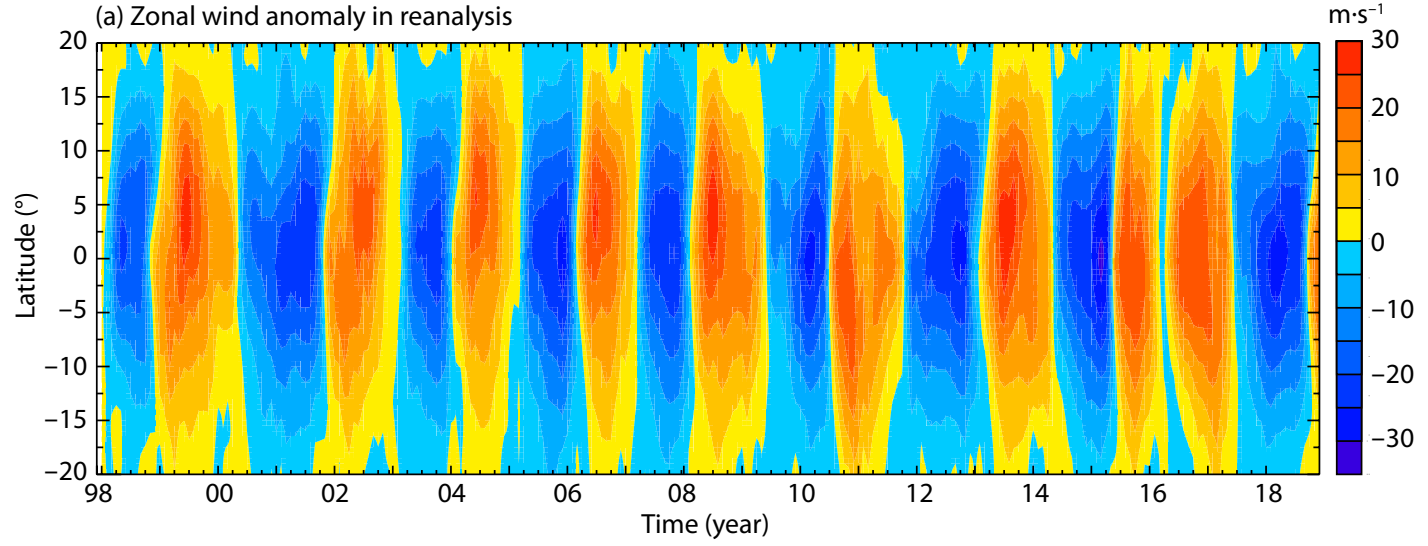

(b) Temperature anomaly in reanalysis

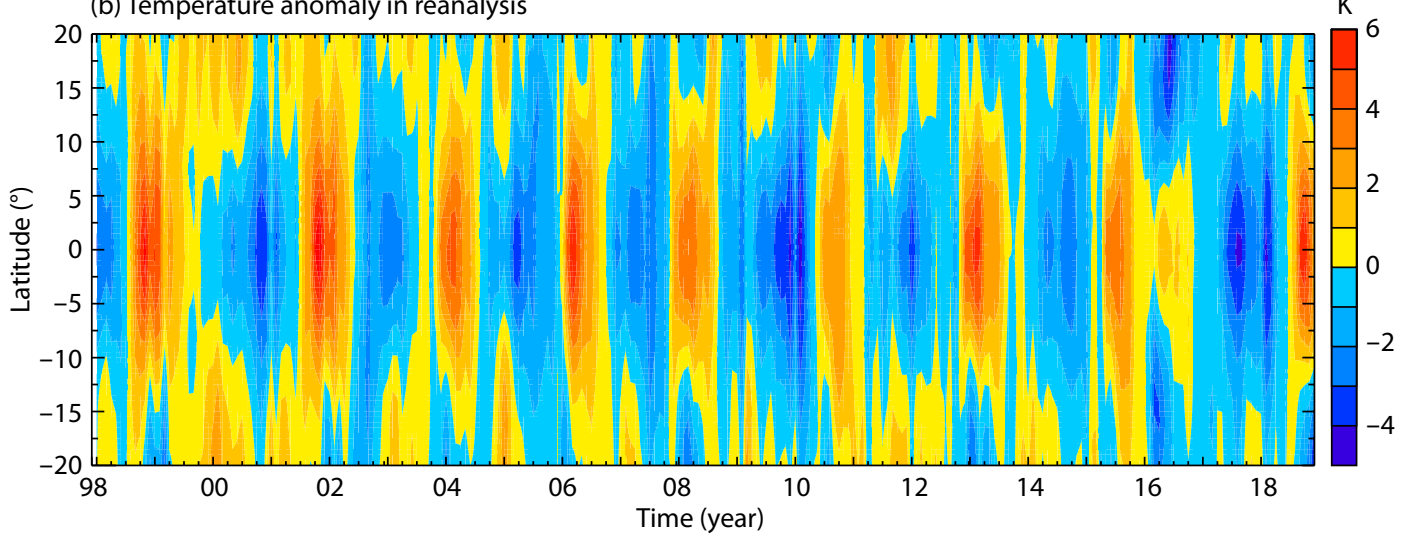

Figure 5. Latitude-time section of monthly mean (a) zonal wind and (b) temperature anomalies at $28.4 \mathrm{hPa}$ between $20^{\circ} \mathrm{S}$ and $20^{\circ} \mathrm{N}$ along the $158.13^{\circ} \mathrm{E}$ meridian line. 

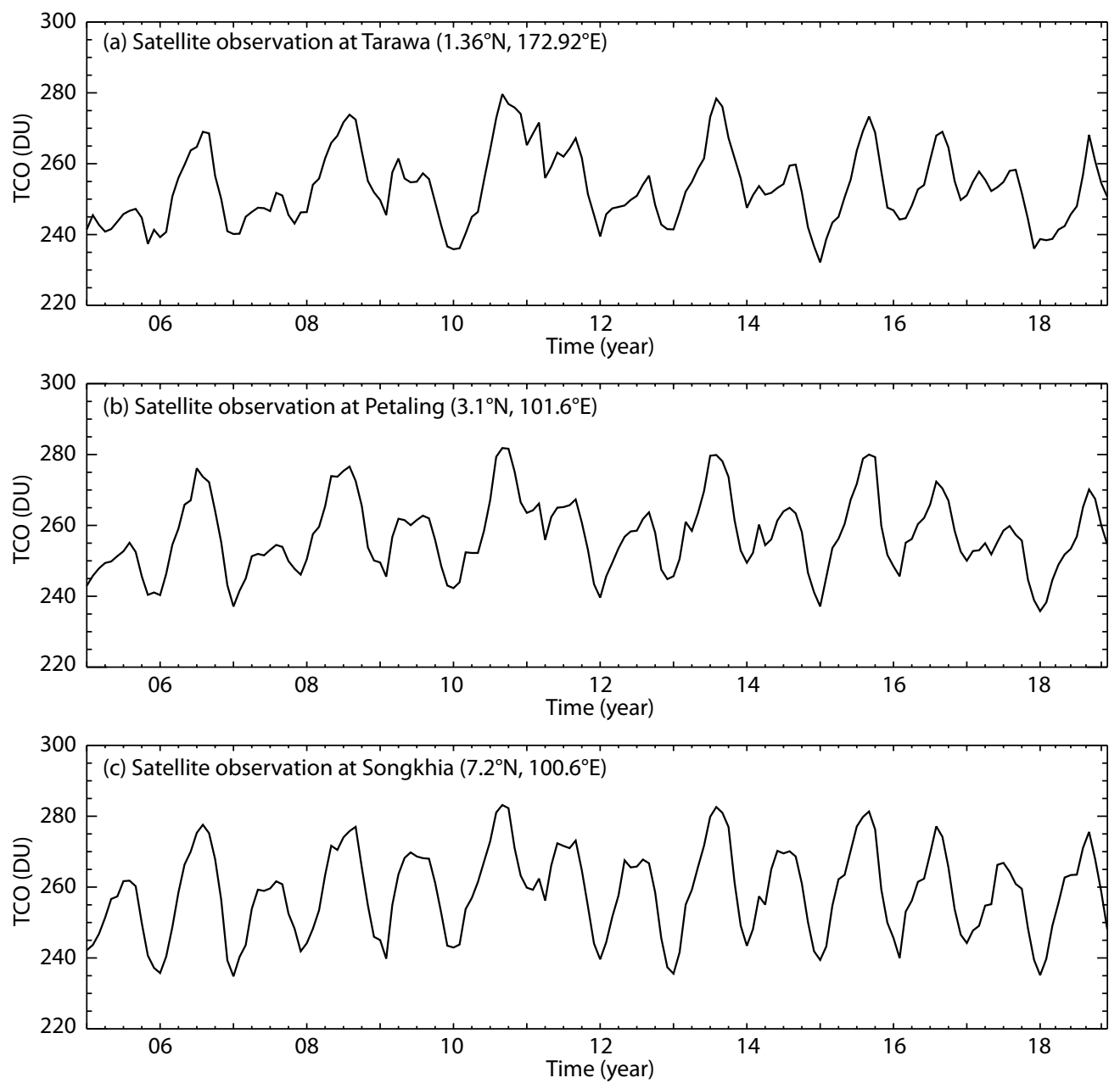

Figure 6. Monthly mean total column ozone at (a) Tarawa, (b) Petaling and (c) Songkhia derived from the Aura satellite ozone monitoring instrument.

the residual mean vertical velocity $\left(w^{*}\right)$ anomaly is in approximate thermodynamic balance with the heating rate anomaly $Q$, which is written as follows (Randel et al., 1999):

$$
w^{*} \frac{H N^{2}}{R} \simeq Q \text {, }
$$

where $N$ is the buoyant frequency. Then, assuming that the radiative heating anomaly $Q$ associated with the $\mathrm{QBO}$ approximately meets a Newtonian cooling relationship with the QBO temperature anomaly (i.e., $Q=-a \delta T_{\mathrm{QBO}}$ ), we obtain the expression:

$$
w^{*} \simeq-\frac{a R}{H N^{2}} \delta T_{\mathrm{QBO}}
$$

where $a$ is the inverse radiative damping coefficient. This indicates that a warm (cold) QBO temperature anomaly induces a relatively downward (upward) moving flow due to radiative cooling (heating). Hence, as shown in Figure 8, the positive ozone QBO phase below $\sim 30 \mathrm{~km}$ is in good agreement with the warm phase of the temperature QBO because the sinking flow carries ozonerich air from the higher levels, and the converse is also true. However, in the middle stratosphere $>30 \mathrm{~km}$, ozone has a short lifetime and is controlled by photochemical reactions (Hasebe, 1994; Randel and Wu F, 1996; Jones et al., 1998). In this way, the ozone QBO exhibits an anti-phase relation with the temperature QBO. One can see from Figure 8 that the less positive phase of the ozone QBO at 20-30 km corresponds to the weakly warm phase of the temperature QBO in 2016-2017. Owing to the absence of the warm temperature phase above $30 \mathrm{~km}$ in this anomalous QBO event, there exists a very long positive phase of the ozone QBO from 2015 to 2017; thus the double-peak structure of the ozone QBO with approximate in-phase instead of anti-phases appears in the lower and middle stratosphere in 2016-2017. Therefore, the anomalous QBO presents not only in the zonal wind studied extensively, but also in the temperature and ozone from the lower to middle stratosphere.

\section{Summary}

The anomalous QBO in the zonal wind during the winter of 2015-2016 has been well-studied. In this paper, we investigate the anomalous change in the temperature and ozone QBOs further by combining radiosonde and satellite observations at tropical stations and MERRA-2 reanalysis data.

The radiosonde observations indicate that the alternating phase QBO pattern in temperature is similar to that in the zonal wind but with an approximate quarter cycle out of phase. The zonal wind 

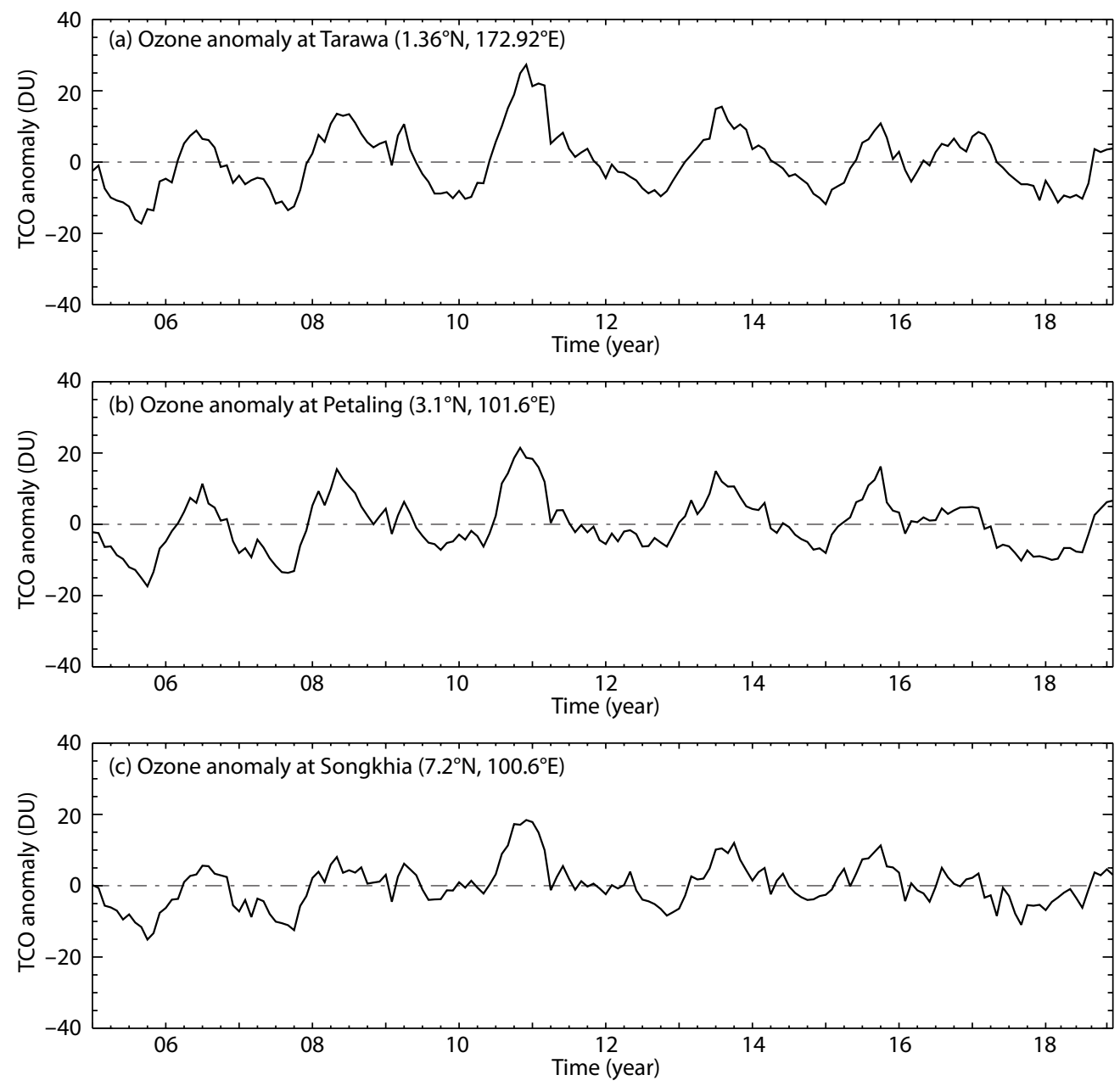

Figure 7. Monthly mean total column ozone anomalies at (a) Tarawa, (b) Petaling and (c) Songkhia derived from the Aura ozone monitoring instrument between January 2005 and December 2018.

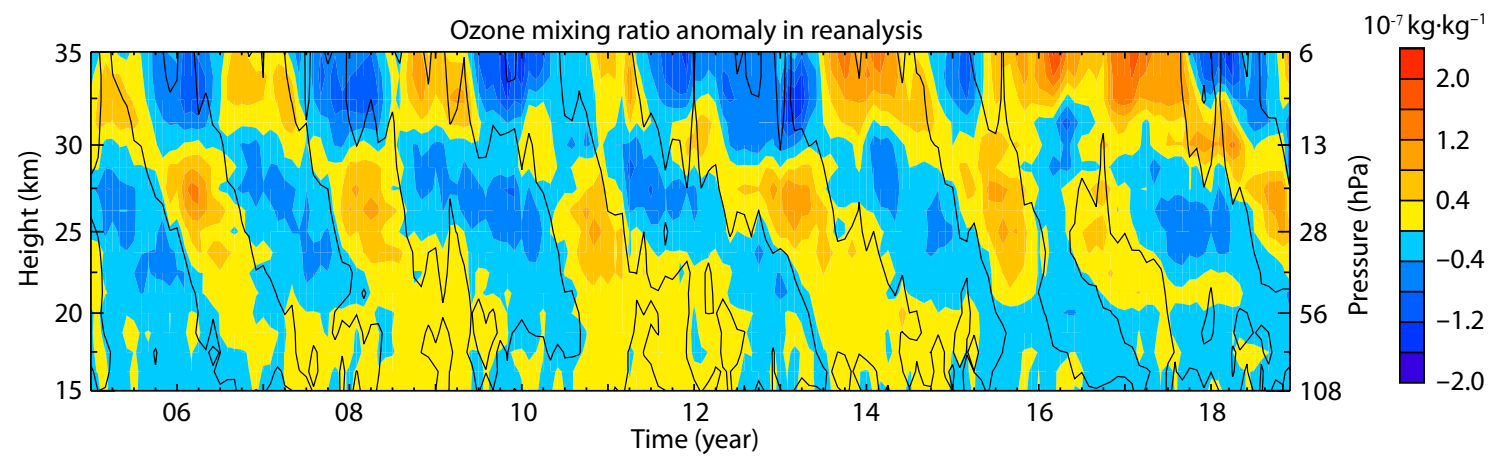

Figure 8. Time-height section of monthly mean ozone mixing ratio anomaly over Ponape Island from MERRA-2 reanalysis data between January 2005 and December 2018. The black lines are the zero lines of temperature anomaly derived from the reanalysis data in Panel $3 \mathrm{~b}$.

QBO is accompanied together with the temperature oscillation, and the positive (negative) wind shear is associated with the warm (cold) temperature anomaly. As the upward propagating eastward phase of the zonal wind QBO takes the place of the regular descending westward phase at $\sim 24-30 \mathrm{~km}$ in the winter of 2015-2016, the vertical wind shear is changed from the normal negative to positive values in the height range of $\sim 20-27 \mathrm{~km}$. Thus a corresponding change occurs in the temperature $\mathrm{QBO}$ that has the shortest cold phase at $21-27 \mathrm{~km}$ in the data record. Even so, the downward moving cold phase is not completely replaced by a warm phase. The unexpected ascending eastward wind decreases with height and stalls at about $35 \mathrm{~km}$, which leads to a westward wind shear above $27 \mathrm{~km}$. Accordingly, an extremely long cold phase above almost $27 \mathrm{~km}$ lasts for 2-3 years from 2015 to 2017 , owing to the absence of the corresponding warm phase. The reanalysis data exhibits that the meridional extension of the 
temperature QBO in 2016 is obviously smaller than in the other years, implying a smaller QBO temperature anomaly according to the thermal wind balance. This causes the relationship between the temperature anomaly and wind shear, from the winter of 2015-2016 to the spring of 2017, to look different from other regular QBO cycles. Hence, the anomalous zonal wind QBO causes the anomalous change of temperature $\mathrm{QBO}$ in both the vertical and meridional directions.

The OMI measurement reveals that the QBO is the dominant interannual variability of the TCO in the tropics. With the anomalous changes of the zonal wind and temperature QBOs, the QBO in the TCO turns from the normal fall to slow-rise phase in the winter of 2015-2016, and its next amplitude peak in the winter of 2016-2017 is evidently smaller than in the other regular QBO cycles. This is related to the weakly warm phase of the temperature QBO below $30 \mathrm{~km}$ since ozone is mainly concentrated at 20 to $30 \mathrm{~km}$. The reanalysis data shows a double-peak structure of the QBO in the ozone mixing ratio with an inverse phase relationship, and the ozone QBO phase below (above) $30 \mathrm{~km}$ is in agreement with (opposite to) the phase of the temperature QBO due to the different control mechanisms. The anomalous QBO event leads to the weakly warm phase of the temperature QBO below $30 \mathrm{~km}$ in 2016-2017, thus there is a less positive phase of the ozone QBO at 20-30 km. Because of the absence of the warm temperature phase above $30 \mathrm{~km}$, a very long positive phase of the ozone QBO appears above $30 \mathrm{~km}$ from 2015 to 2017 . Therefore, the anomalous changes occur not only in the zonal wind QBO but also in the temperature and ozone QBOs from the lower to middle stratosphere.

\section{Acknowledgments}

We are grateful to the editor and anonymous reviewers for their valuable comments on our paper. We thank NOAA for providing the radiosonde data at http://www.sparc.sunysb.edu/, ESA for providing the TCO data at http://www.temis.nl/protocols/ o3field/data/omi/, and NASA for providing the MERRA-2 dataset at https://disc.gsfc.nasa.gov/datasets/. This work was jointly supported by the National Natural Science Foundation of China (through grants 41974176 and 41674151).

\section{References}

Andrews, D. G., Holton, J. R., and Leovy, C. B. (1987). Middle Atmosphere Dynamics. San Diego: Academic Press. https://doi.org/10.1002/qj.49711548612

Baldwin, M. P., Gray, L. J., Dunkerton, T. J., Hamilton, K., Haynes, P. H., Randel, W. J., Holton, J. R., Alexander, M. J., Hirota, I., ... Takahashi, M. (2001). The quasibiennial oscillation. Rev. Geophys., 39(2), 179-229. https://doi.org/10.1029/1999RG000073

Barton, C. A., and McCormack, J. P. (2017). Origin of the 2016 QBO disruption and its relationship to extreme El Niño events. Geophys. Res. Lett., 44(21), 11150-11157. https://doi.org/10.1002/2017GL075576

Coy, L., Newman, P. A., Pawson, S., and Lait, L. R. (2017). Dynamics of the disrupted 2015/16 quasi-biennial oscillation. J. Climate, 30(15), 5661-5674. https://doi.org/10.1175/JCLI-D-16-0663.1

Dunkerton, T. J., and Delisi, D. P. (1985). Climatology of the equatorial lower stratosphere. J. Atmos. Sci., 42(4), 376-396. https://doi.org/10.1175/15200469(1985)042<0376:cotels>2.0.c0;2

Dunkerton, T. J. (1997). The role of gravity waves in the quasi-biennial oscillation. J. Geophys. Res. Atmos., 102(D22), 26053-26076. https://doi.org/10.1029/96jd02999

Dunkerton, T. J. (2016). The quasi-biennial oscillation of 2015-2016: hiccup or death spiral?. Geophys. Res. Lett., 43(19), 10547-10552.

https://doi.org/10.1002/2016gl070921

Ebdon, R. A. (1960). Notes on the wind flow at $50 \mathrm{mb}$ in tropical and subtropical regions in January 1957 and January 1958. Quart. J. Roy. Meteor. Soc., 86(370), 540-542. https://doi.org/10.1002/qj.49708637011

Eluszkiewicz, J., Crisp, D., Zurek, R., Elson, L., Fishbein, E., Froidevaux, L., Waters, J., Grainger, R. G., Lambert, A., ... Peckham, G. (1996). Residual circulation in the stratosphere and lower mesosphere as diagnosed from Microwave limb sounder data. J. Atmos. Sci., 53(2), 217-240. https://doi.org/10.1175/15200469(1996)053<0217:rcitsa>2.0.co;2

Fadnavis, S., and Beig, G. (2009). Quasi-biennial oscillation in ozone and temperature over tropics. J. Atmos. Sol. Terr. Phys., 71(2), 257-263. https://doi.org/10.1016/j.jastp.2008.11.012

Fleming, E. L., Jackman, C. H., Rosenfield, J. E., and Considine, D. B. (2002). Twodimensional model simulations of the QBO in ozone and tracers in the tropical stratosphere. J. Geophys. Res. Atmos., 107(D23), 4665. https://doi.org/10.1029/2001jd001146

Garcia, R. R., and Solomon, S. (1985). The effect of breaking gravity waves on the dynamics and chemical composition of the mesosphere and lower thermosphere. J. Geophys. Res. Atmos., 90(D2), 3850-3868. https://doi.org/10.1029/JD090iD02p03850

Gelaro, R., McCarty, W., Suárez, M. J., Todling, R., Molod, A., Takacs, L., Randles, C. A., Darmenov, A., Bosilovich, M. G., ... Zhao, B. (2017). The modern-era retrospective analysis for research and applications, Version 2(MERRA-2). J. Climate, 30(14), 5419-5454. https://doi.org/10.1175/JCLI-D-16-0758.1

Hasebe, F. (1994). Quasi-biennial oscillations of ozone and diabatic circulation in the equatorial stratosphere. J. Atmos. Sci., 51(5), 729-745. https://doi.org/10.1175/1520-0469(1994)051<0729:QBOOOA>2.0.CO;2

Holton, J. R., and Lindzen, R. S. (1972). An updated theory for the quasi-biennial cycle of the tropical stratosphere. J. Atmos. Sci., 29(6), 1076-1080. https://doi.org/10.1175/1520-0469(1972)029<1076:autftq >2.0.co;2

Huang, K. M., Zhang, S. D., Yi, F., and Chen, Z. Y. (2009). Simulation of the equatorial quasi-biennial oscillation based on the parameterization of continuously spectral gravity waves. Chin. Sci. Bull., 54(2), 288-295. https://doi.org/10.1007/s11434-008-0409-z

Jones, D. B. A., Schneider, H. R., and McElroy, M. B. (1998). Effects of the quasibiennial oscillation on the zonally averaged transport of tracers. J. Geophys. Res. Atmos., 103(D10), 11235-11249. https://doi.org/10.1029/98JD00682

Kerminen, V. M., Niemi, J. V., Timonen, H., Aurela, M., Frey, A., Carbone, S., Saarikoski, S., Teinilä, K., Hakkarainen, J., ... Hillamo, R. (2011). Characterization of a volcanic ash episode in southern Finland caused by the Grimsvötn eruption in Iceland in May 2011. Atmos. Chem. Phys. Discuss., 11(23), 24933-24968. https://doi.org/10.5194/acpd-11-24933-2011

Lee, S., Shelow, D. M., Thompson, A. M., and Miller, S. K. (2010). QBO and ENSO variability in temperature and ozone from SHADOZ, 1998-2005. J. Geophys. Res. Atmos., 115(D18), D18105. https://doi.org/10.1029/2009jd013320

Li, H. Y., Kedzierski, P. P., and Matthes, K. (2020). On the forcings of the unusual quasi-biennial oscillation structure in February 2016. Atmos. Chem. Phys., 20(11), 6541-6561. https://doi.org/10.5194/acp-20-6541-2020

Lin, P., Held, I., and Ming, Y. (2019). The early development of the 2015/16 quasi-biennial oscillation disruption. J. Atmos. Sci., 76(3), 821-836. https://doi.org/10.1175/JAS-D-18-0292.1

Ling, X. D., and London, J. (1986). The quasi-biennial oscillation of ozone in the tropical middle stratosphere: a one-dimensional model. J. Atmos. Sci., 43(24), 3122-3137. https://doi.org/10.1175/15200469(1986)043<3122:TQBOOO>2.0.CO;2

Liu, J. H., Rodriguez, J. M., Oman, L. D., Douglass, A. R., Olsen, M. A., and Hu, L. (2020). Stratospheric impact on the Northern Hemisphere winter and spring ozone interannual variability in the troposphere. Atmos. Chem. Phys., 20(11), 6417-6433. https://doi.org/10.5194/acp-20-6417-2020

McCormack, J. P., and Siskind, D. E. (2002). Simulations of the quasi-biennial oscillation and its effect on stratospheric $\mathrm{H}_{2} \mathrm{O}, \mathrm{CH}_{4}$, and age of air with an 
interactive two-dimensional model. J. Geophys. Res. Atmos., 107(D22), ACL 71-ACL 7-17. https://doi.org/10.1029/2002jd002141

Naujokat, B. (1986). An update of the observed quasi-biennial oscillation of the stratospheric winds over the tropics. J. Atmos. Sci., 43(17), 1873-1877. https://doi.org/10.1175/1520-0469(1986)043<1873:auotoq >2.0.co;2

Newman, P. A., Coy, L., Pawson, S., and Lait, L. R. (2016). The anomalous change in the QBO in 2015-2016. Geophys. Res. Lett., 43(16), 8791-8797. https://doi.org/10.1002/2016GL070373

Osprey, S. M., Butchart, N., Knight, J. R., Scaife, A. A., Hamilton, K., Anstey, J. A., Schenzinger, V., and Zhang, C. X. (2016). An unexpected disruption of the atmospheric quasi-biennial oscillation. Science, 353(6306), 1424-1427. https://doi.org/10.1126/science.aah4156

Pascoe, C. L., Gray, L. J., Crooks, S. A., Juckes, M. N., and Baldwin, M. P. (2005). The quasi-biennial oscillation: analysis using ERA-40 data. J. Geophys. Res. Atmos., 110(D8), D08105. https://doi.org/10.1029/2004JD004941

Plumb, R. A., and Bell, R. C. (1982). A model of the quasi-biennial oscillation on an equatorial beta-plane. Quart. J. Roy. Meteor. Soc., 108(456), 335-352. https://doi.org/10.1002/qj.49710845604

Randel, W. J., and Cobb, J. B. (1994). Coherent variations of monthly mean total ozone and lower stratospheric temperature. J. Geophys. Res. Atmos., 99(D3), 5433-5447. https://doi.org/10.1029/93JD03454

Randel, W. J., and Wu, F. (1996). Isolation of the ozone QBO in SAGE II data by singular-value decomposition. J. Atmos. Sci., 53(17), 2546-2559. https://doi.org/10.1175/1520-0469(1996)053<2546:IOTOQI>2.0.CO;2

Randel, W. J., Wu, F., Swinbank, R., Nash, J., and O'Neill, A. (1999). Global QBO circulation derived from UKMO stratospheric analyses. J. Atmos. Sci., 56(4), 457-474. https://doi.org/10.1175/15200469(1999)056<0457:GQCDFU>2.0.CO;2

Rao, J., and Ren, R. C. (2017). Parallel comparison of the 1982/83, 1997/98 and 2015/16 super El Niños and their effects on the extratropical stratosphere. Adv. Atmos. Sci., 34(9), 1121-1133. https://doi.org/10.1007/s00376-0176260-x

Rao, J., Yu, Y. Y., Guo, D., Shi, C. H., Chen, D., and Hu, D. Z. (2019). Evaluating the brewer-dobson circulation and its responses to ENSO, QBO, and the solar cycle in different reanalyses. Earth Planet. Phys., 3(2), 166-181. https://doi.org/10.26464/epp2019012

Rao, J., Garfinkel, C. I., and White, I. P. (2020a). Impact of the quasi-biennial oscillation on the northern winter stratospheric polar vortex in CMIP5/6 Models. J. Climate, 33(11), 4787-4813. https://doi.org/10.1175/JCLI-D-190663.1
Rao, J., Garfinkel, C. I., and White, I. P. (2020b). How does the quasi-biennial oscillation affect the boreal winter tropospheric circulation in CMIP5/6 Models?. J. Climate, 33(20), 8975-8996. https://doi.org/10.1175/JCLI-D-200024.1

Reed, R. J., Campbell, W. J., Rasmussen, L. A., and Rogers, D. G. (1961). Evidence of a downward-propagating, annual wind reversal in the equatorial stratosphere. J. Geophys. Res., 66(3), 813-818. https://doi.org/10.1029/JZ066i003p00813

Ribera, P., Peña-Ortiz, C., Garcia-Herrera, R., Gallego, D., Gimeno, L., and Hernández, E. (2004). Detection of the secondary meridional circulation associated with the quasi-biennial oscillation. J. Geophys. Res. Atmos., 109(D18), D18112. https://doi.org/10.1029/2003JD004363

Tegtmeier, S., Fioletov, V. E., and Shepherd, T. G. (2010). A global picture of the seasonal persistence of stratospheric ozone anomalies. J. Geophys. Res. Atmos., 115(D18), D18119. https://doi.org/10.1029/2009jd013011

Tesche, M., Glantz, P., Johansson, C., Norman, M., Hiebsch, A., Ansmann, A., Althausen, D., Engelmann, R., and Seifert, P. (2012). Volcanic ash over Scandinavia originating from the Grímsvötn eruptions in May 2011. J. Geophys. Res. Atmos., 117(D9), D09201. https://doi.org/10.1029/2011jd017090

Veefkind, J. P., de Haan, J. F., Brinksma, E. J., Kroon, M., and Levelt, P. F. (2006). Total ozone from the ozone monitoring instrument (OMI) using the DOAS technique. IEEE Trans. Geosci. Remote Sens., 44(5), 1239-1244. https://doi.org/10.1109/TGRS.2006.871204

Wallace, J. M., Panetta, R. L., and Estberg, J. (1993). Representation of the equatorial stratospheric quasi-biennial oscillation in EOF phase space. J. Atmos. Sci., 50(12), 1751-1762. https://doi.org/10.1175/15200469(1993)050<1751:ROTESQ > 2.0.CO;2

Weaver, C. J., Douglass, A. R., and Rood, R. B. (1993). Thermodynamic balance of three-dimensional stratospheric winds derived from a data assimilation procedure. J. Atmos. Sci., 50(17), 2987-2993. https://doi.org/10.1175/15200469(1993)050<2987:TBOTDS>2.0.CO;2

Xue, X. H., Liu, H. L., and Dou, X. K. (2012). Parameterization of the inertial gravity waves and generation of the quasi-biennial oscillation. J. Geophys. Res. Atmos., 117(D6), D06103. https://doi.org/10.1029/2011JD016778

Zawodny, J. M., and McCormick, M. P. (1991). Stratospheric aerosol and gas experiment II measurements of the quasi-biennial oscillations in ozone and nitrogen dioxide. J. Geophys. Res. Atmos., 96(D5), 9371-9377. https://doi.org/10.1029/91jd00517 